\title{
Tarefa de discriminação de fonemas com pseudopalavras"
}

\author{
Rui Rothe-Neves \\ Regina Carla Lapate \\ Juliana Sardinha Pinto \\ Universidade Federal de Minas Gerais
}

\section{Abstract}

This paper presents a task for phoneme discrimination as part of a more comprehensive set of tasks for psycholinguistic assessment of language currently under development (TAL-UFMG). The task consists of 40 pairs of monosyllabic nonwords, from which 20 pairs are made of two copies of the same syllable and 20 pairs differ in relation to one single feature (voice, place or mode of articulation) of their first consonant. This list of syllable pairs was presented in random order to 8 adult aphasic patients (experimental group) and 55 normal young adults (control group). Participants were asked to indicate after each pair whether it consisted of either equal or different syllables. The experimental group made 60.6\% correct answers versus $97.5 \%$ by the control group. Differences were larger among voiced/unvoiced stimuli. The consistency of the task (Kuder-Richardson) for the experimental group was 0.823 . Thus, the task is able to distinguish between normal and abnormal populations and, within each, between stimulus differences. 


\section{INTRODUÇÃO}

$\mathrm{E}$

ste artigo apresenta uma tarefa de discriminação de fonemas, parte integrante de um conjunto de tarefas de avaliação psicolingüística atualmente em desenvolvimento (TALUFMG). Na abordagem psicolingüística de avaliação (CAPLAN, 1992; ROTHE-NEVES \& CAMARGOS, 2000), as tarefas são planejadas de modo a permitir a avaliação controlada dos sub-processos de produção e compreensão de linguagem. Portanto, não se trata de tarefas de avaliação de distúrbios ou patologias específicas de adultos ou crianças, mas tarefas que visam avaliar o funcionamento adequado dos diversos processos envolvidos na linguagem - a disfunção pode ser inferida a partir da comparação com o desempenho funcional, próximo a $100 \%$. As tarefas comumente utilizadas no País para investigar o nível fonêmico da linguagem por meio da habilidade de discriminar fonemas, em geral, não cumprem esse requisito, pelos motivos discutidos a seguir.

O método mais utilizado para avaliar a discriminação de fonemas do português brasileiro (PB) em contexto clínico é o da repetição de palavras e pseudopalavras (ou logatomas), palavras inventadas que, embora sem sentido, obedecem às regras fonotáticas da língua (revisão em CHAVES; NEPOMUCENO; ROSSI; MOTA; PILLON, 1999; ver também DELGADO; BEVILACQUA, 1999; LONGONI; BORGES, 1997). Apresentam-se palavras e pseudopalavras ao sujeito, que deve repeti-las, e o escore da tarefa consiste na proporção de estímulos repetidos corretamente. A primeira observação crítica que se pode fazer em relação a esse método diz respeito ao comprometimento da repetição em pacientes com déficits articulatórios. O comportamento exigido como resposta não distingue erros provocados pelo prejuízo de natureza articulatória daqueles perceptivos. Se é desnecessário supor tais dificuldades em pacientes portadores de perda auditiva, 
o mesmo não ocorre na afasia. Além do prejuízo à motricidade oral, que pode ser considerável, Varney (1984) estimou em 18\% a proporção de pacientes afásicos com dificuldades na discriminação de fonemas. Da revisão da literatura oferecida em Chaves et. al. (op. cit., p.54) e Penrod (1989), depreende-se, ainda, duas limitações do método. Estímulos como palavras polissílabas ou frases inteiras oferecem pistas fonotáticas, prosódicas e semânticas, o que, por sua vez, podem servir à discriminação de fonemas. Além disso, ao se utilizarem palavras que de fato existem na língua, aparentemente supõe-se que a discriminação de fonemas não sofra influência de pistas semânticas. Superestima-se, assim, uma visão estritamente seqüencial do processamento lingüístico, a despeito da existência de propostas teóricas (ver revisão em ROTHE-NEVES; HAASE, 2000) e evidências experimentais em contrário (p.ex., MARSLEN-WILSON; TYLER, 1980). A partir dessas observações críticas, pode-se concluir que, embora o método da repetição possa servir ad hoc, não é adequado para uma avaliação da discriminação de fonemas que vise colher informações de grupos não-clínicos e clínicos de vários tipos.

Para superar tais dificuldades, a tarefa deve visar à avaliação da capacidade de distinguir traços característicos de fonemas, controlando variáveis externas, tais como a influência do status semântico, e dispensar o uso da linguagem na resposta. Desde Miller \& Nicely (1955), sabe-se que a discriminação de consoantes oferece maior dificuldade quando se manipula apenas um traço distintivo. Na literatura psicoacústica, a mais simples avaliação comportamental da percepção é feita pelo procedimento de "escolha forçada de uma alternativa" ou procedimento "sim-não" (yes-no procedure). No contexto clínico, Caplan (1992) sugere uma tarefa com tais características. Apresentamse ao sujeito 40 pares de pseudopalavras, sendo 20 de monossílabos idênticos e 20 distintos, em ordem aleatória. Os pares distintos diferem com relação a um único traço de um fonema consonantal (ponto de articulação, modo de articulação ou vozeamento). O fonema diferente pode ocorrer no início ou no final do estímulo e a consoante é seguida da vogal /a/. "As consoantes foram escolhidas como os segmentos a serem alterados porque têm sido usadas mais 
freqüentemente do que vogais em pesquisa de discriminação de fonemas na afasia" (CAPLAN, 1992, p.408). Como resposta, a pessoa deve apenas informar se os dois itens são idênticos, o que pode ser feito por meio de qualquer sinal convencionado.

O escore é a proporção de respostas corretas. No presente trabalho, visamos construir e avaliar uma tarefa desse tipo com fonemas do PB.

\section{MÉTODO}

\section{Materiais}

A tarefa compreende 40 pares de sílabas sem sentido, sendo 20 pares compostos por duas sílabas idênticas e outros 20 pares, por duas sílabas que diferem apenas quanto a um único traço (ponto, modo ou vozeamento) nas consoantes iniciais. Para a escolha dos estímulos, sílabas fechadas foram compostas por permutação aleatória. Ao contrário do sugerido por Caplan, optamos por sílabas fechadas em que todas as vogais possam ocorrer, a fim de diversificar o contexto articulatório, o que aumenta a validade ecológica da tarefa. Como as sílabas foram escolhidas aleatoriamente, a influência do contexto não é sistemática. Utilizaram-se todos os fonemas consonantais e vocálicos existentes e combinados adequadamente no PB. Excluíram-se, então, as sílabas existentes como palavras do léxico (p.ex.: [max]). Dentre as demais, selecionaram-se aleatoriamente 40 sílabas, das quais 20 foram duplicadas, formando os pares idênticos. Para as demais 20 sílabas, foram produzidos os pares respectivos, cuja consoante inicial difere num único traço. Os pares de sílabas assim produzidos foram lidos por uma profissional e registradas digitalmente (44,1 kHz, 16-bit). ${ }^{1} \mathrm{O}$ material foi editado a fim de apresentar 0,2 s entre as sílabas e $5 \mathrm{~s}$ entre cada par (cf. CAPLAN \& UTMAN, 1994). Todos os pares foram então ordenados aleatoriamente.

\section{Amostras}

A fim de avaliar a aplicabilidade da tarefa, investigaram-se seus resultados em dois grupos de sujeitos. O grupo experimental $(n=8)$ 
consistiu de pacientes afásicos adultos selecionados, após consentimento livre e informado, dentre os indivíduos com lesão cerebral atendidos na Clínica de Fonoaudiologia do HC-UFMG. Os pacientes não receberam nenhum tipo de remuneração para colaborar com a pesquisa, mas os resultados foram disponibilizados aos profissionais que os assistem. O grupo controle $(n=55)$ consistiu de jovens adultos, selecionados dentre estudantes de curso de graduação em Psicologia (UFMG), que receberam créditos por sua participação na pesquisa.

\section{Procedimento}

Os estímulos foram apresentados individualmente em campo aberto em sala silenciosa. Os sujeitos indicaram sua resposta verbalmente ou por escrito. Alternativamente, a pessoa poderia indicar sua resposta por meio de um cartão contendo duas figuras: a figura da direita apresentava a palavra IGUAL e três quadrados vermelhos, que representavam o conceito "igual"; a da esquerda, a palavra DIFERENTE e três figuras geométricas distintas (círculo, quadrado e triângulo), cada qual de uma cor, também representando o conceito a que se referiam. Essa alternativa foi utilizada quando as dificuldades motoras dos sujeitos do grupo experimental impediram-nos de responder das outras maneiras. Em todos os casos, a resposta era registrada pelo examinador imediatamente. Para cada sujeito registrou-se a proporção de acerto.

\section{RESULTADOS E DISCUSSÃO}

Como se poderia esperar, os resultados do grupo controle mostraram maior proporção de acerto do que os do grupo experimental (TAB. 1). A hipótese nula de que os resultados de cada grupo foram idênticos para erros e acertos foi testada por meio do teste c 2 . O comportamento observado nos dados difere significativamente da hipótese nula no grupo experimental $(c 2=4,241, \mathrm{p}<0,05)$, mas principalmente no grupo controle $(c=10,935, \mathrm{p}<0,001)$. Nos pares de teste, também foi possível notar diferenças entre o traço manipulado (TAB. 2), sendo a mais significativa nos pares cuja consoante inicial se distingue por modo de articulação. Tanto no grupo experimental 
quanto no controle, houve mais erros nos pares que se distinguem pelo vozeamento da consoante inicial. Também foi possível notar diferenças em cada par apresentado. Isto mostra que a tarefa, foco do estudo, permite de fato investigar diferenças entre grupos clínicos e não-clínicos.

TABELA 1 - Resposta dos grupos em relação ao tipo de estímulo.

\begin{tabular}{|l|c|c|c|c|c|c|}
\hline ITENS & \multicolumn{6}{|c|}{ GRUPOS } \\
\hline & \multicolumn{2}{|c|}{ Experimental $(\mathrm{n}=8)$} & \multicolumn{2}{c|}{ Controle $(\mathrm{n}=55)$} \\
\hline & Acerto & Erro & Total & Acerto & Erro & Total \\
\hline Distratores & $106(33,1 \%)$ & $54(16,9 \%)$ & $160(50 \%)$ & $1085(49,3 \%)$ & $15(0,7 \%)$ & $1100(50 \%)$ \\
\hline Teste & $88(27,5 \%)$ & $72(22,5 \%)$ & $160(50 \%)$ & $1061(48,2 \%)$ & $39(1,8 \%)$ & $1100(50 \%)$ \\
\hline TOTAL & $194(60,6 \%)$ & $126(39,4 \%)$ & $320(100 \%)$ & $2146(97,5 \%)$ & $54(2,5 \%)$ & $2200(100 \%)$ \\
\hline
\end{tabular}

TABELA 2 - Proporção de acerto dos grupos nos pares de teste

\begin{tabular}{|c|c|c|c|}
\hline \multirow[t]{2}{*}{ OPOSIÇÕES } & & \multicolumn{2}{|c|}{ GRUPOS } \\
\hline & & Experimental $(\mathrm{n}=8)$ & Controle $(n=55)$ \\
\hline \multirow[t]{8}{*}{ Ponto } & ט 3 & 0,875 & 0,982 \\
\hline & $t \mathrm{k}$ & 1 & 1 \\
\hline & $f \int$ & 0,625 & 1 \\
\hline & b g & 0,625 & 0,945 \\
\hline & $f s$ & 0,75 & 0,982 \\
\hline & $\mathrm{m} \mathrm{n}$ & 0,5 & 0,982 \\
\hline & b d & 0,25 & 1 \\
\hline & média & 0,661 & 0,984 \\
\hline \multirow[t]{7}{*}{ Modo } & $d z$ & 1 & 0,982 \\
\hline & $\mathrm{n} 1$ & 0,75 & 1 \\
\hline & $d n$ & 0,625 & 1 \\
\hline & $t \int S$ & 0,5 & 0,982 \\
\hline & $t s$ & 0,625 & 0,982 \\
\hline & $\mathrm{z} \mathrm{n}$ & 0,5 & 1 \\
\hline & média & 0,667 & 0,991 \\
\hline \multirow[t]{8}{*}{ Voz } & $\int 3$ & 0,25 & 0,982 \\
\hline & $t d$ & 0,25 & 0,6 \\
\hline & $s z$ & 0,25 & 0,964 \\
\hline & $\mathrm{kg}$ & 0,5 & 1 \\
\hline & $\mathrm{p} \mathrm{b}$ & 0,375 & 0,982 \\
\hline & $f v$ & 0,375 & 1 \\
\hline & $t \int d 3$ & 0,375 & 0,927 \\
\hline & média & 0,339 & 0,922 \\
\hline
\end{tabular}


Uma estatística relevante, nesse contexto em que se avalia uma tarefa, é o coeficiente de consistência, por meio do qual se pode conhecer a consistência entre itens ou a homogeneidade da tarefa. Uma alta consistência indica a confiabilidade da tarefa. Para o caso, o procedimento mais utilizado é o cálculo do coeficiente $r_{t t}$ de KuderRichardson (cf. ANASTASI \& URBINA, 2000, p.94), pois a tarefa aqui examinada exige respostas "sim-não" a cada item. A consistência da tarefa é satisfatória $\left(\mathrm{r}_{\mathrm{tt}}=.82\right)$, quando examinadas as respostas do grupo experimental. $\mathrm{O}$ valor do coeficiente pode ser interpretado diretamente, como a proporção de variância devida à tarefa e não a erros sistemáticos. Isto é, $82 \%$ da variância nos resultados são devidos ao que se quer medir de fato. No entanto, o coeficiente $r_{t t}$ deve ser tomado, aqui, com cautela, na medida em que é sensível ao número de itens, à quantidade de acertos e à variância e, com isso, ao tamanho da amostra. Enquanto o grupo experimental tem variância notável, a amostra é pequena. O grupo controle apresenta características opostas: bom número e variância desprezível, pois quase todos discriminaram corretamente os itens. A relação entre essas estatísticas e seu efeito pode ser vista ao compararmos o $r_{t t}$ do grupo experimental, do grupo controle e, também, apenas para ilustração, de um grupo fictício formado por ambos os grupos juntos (TAB. 3). Esse último serve aqui para mostrar que, com maior variância e quantidade de acertos e sujeitos, o $r_{t t}$ seria, provavelmente, melhor - uma questão a ser futuramente investigada.

TABELA 3 - Consistência (rtt de KUDER-RICHARDSON) e estatísticas relevantes

\begin{tabular}{l|lll}
\hline \multirow{2}{*}{ GRUPO } & \multicolumn{3}{|c}{ ESTATÍSTICA } \\
\cline { 2 - 4 } & Variância & $\Sigma \mathrm{pq}$ & $\mathrm{rt}_{\mathrm{t}}$ \\
\hline Experimental & 39,928 & 7,875 & 0,823 \\
Controle & 1,796 & 0,8 & 0,569 \\
Ambos & 97,249 & 2,466 & 0,99963 \\
\hline
\end{tabular}

Um resultado interessante, que suscita novas investigações, é a diferença entre a proporção de acertos nos itens de teste e os distratores. Tecnicamente, o foco recai sobre os itens de teste, feitos 
para possibilitar a distinção entre pessoas com e sem problemas de discriminação. Este objetivo, como se vê, é de fato alcançado pelos itens de teste. No entanto, o grupo experimental também se distinguiu do grupo controle nos itens distratores. Isto pode ser explicado pelo fato de que os distratores ofereceram dificuldade irrisória para o grupo controle, mas o grupo clínico encontrou mesmo aí uma dificuldade maior. Numa futura investigação, será necessário investigar a estrutura de respostas, incluindo, além dos acertos, também os falsos positivos e os falsos negativos, a fim de avaliar a sensibilidade e a especificidade de cada item.

\section{CONCLUSÕES}

A partir dos resultados apresentados, conclui-se que a tarefa de discriminação de fonemas aqui investigada pode ser útil na avaliação dessa capacidade, na medida em que seu procedimento mostrou-se compreensível, adequado às condições clínicas e produziu resultados confiáveis. Do ponto de vista empírico, novos estudos devem comparar a discriminação avaliada nessa e noutra tarefa, de modo a estabelecer estatisticamente sua validade, além da sensibilidade e especificidade dos itens. Também será útil investigar a aplicabilidade da tarefa no contexto do desenvolvimento normal e clínico da linguagem.

\section{NOTAS}

"Este trabalho foi apresentado numa forma preliminar em comunicação ao 7 응 Congresso Brasileiro e $1^{\circ}$ Congresso Internacional de Fonética e Fonologia, Belo Horizonte, 22 a 30/10/2002. É parte integrante do projeto "Testes de avaliação de distúrbios de linguagem: a abordagem psicolingüistica", que contou com financiamento da PRPq/UFMG (convênio 5173*24) e bolsas PIBIC/CNPq (109788/ 2002-8 e 106786/2003-2).

${ }^{1}$ Nesta etapa colaboraram Maurílio Nunes Vieira (Laboratório de Voz, ICEx/UFMG) e Rachel Ferreira Loiola (Unicentro Izabela Hendrix e Programa de Pós-Graduação em Estudos Lingüísticos, POSLIN/UFMG), a quem muito agradecemos. 


\section{REFERÊNCIAS BIBLIOGRÁFICAS}

ANASTASI, A.; URBINA, S. Testagem psicológica. 7.ed. Porto Alegre: Artes Médicas, 2000 .

CAPLAN, D. Language: structure, processing, and disorders. Cambridge, MA: MIT, 1992.

CAPLAN, D.; UTMAN, J. A. Selective acoustic phonetic impairment and lexical access in an aphasic patient. Journal of the Acoustical Society of America, v.95, n.1, p. 512-517, jan. 1994.

CHAVES, A. D.; NEPOMUCENO, L. A.; ROSSI, A. G.; MOTA, H. B.; PILlON, L. Reconhecimento de fala: uma descrição de resultados obtidos em função do número de sílabas dos estímulos. Pró-Fono, v.11, n.1, p.53-58, 1999.

DELGADO, E. M. C.; BEVILACQUA, M. C. Lista de palavras como procedimento de avaliação da percepção dos sons da fala para crianças deficientes auditivas. Pró-Fono, v.11, n.1, p.59-64, 1999.

LONGONI, E.; BORGES, A. C. C. Teste de reconhecimento de fala em indivíduos portadores de perda auditiva neurossensorial. Pró-Fono, v.9, n.1, p.3-9, 1997.

MARSLEN-WILSON, W.; TYLER, L. K. The temporal structure of spoken language understanding. Cognition, v.8, p.1-71, 1980.

MILLER, G. A.; NICELY, P. E. An analysis of perceptual confusions among some English consonants. Journal of the Acoustical Society of America, v.27, p.338352, 1955.

ROTHE-NEVES, R.; CAMARGOS, L. Avaliação de distúrbios de linguagem: a abordagem psicolingüística In: 8 $8^{\text {a }}$ Conferência Internacional de Avaliação Psicológica, 2000, Belo Horizonte. Anais / 5 Encontro Mineiro de Avaliação Psicológica/8 Conferência Internacional de Avaliação Psicológica. São Paulo: Vetor Editora Psicopedagógica, 2002. p.128-130.

ROTHE-NEVES, R.; HAASE, V. G. O "sistema nervoso conceitual" e suas implicações para a avaliação neuropsicológica. II: paradigmas emergentes. Cadernos de Psicologia da Sociedade Brasileira de Psicologia, Ribeirão Preto, v.6, 2000.

PENROD, J. P. Logoaudiometria. In: KATZ, J. (Org.) Tratado de audiologia clínica. São Paulo: Manole, 1989. Cap.10, p. 146-162.

VARNEY, N. L. Phonemic imperception in aphasia. Brain and Language, v.21, p.85-94. 